"Meditations on Drugs":

A Buddhist Ethical Approach

To Pharmaceutical Cognitive Enhancement

By Andrew J. Barnhart

King's College London

Department of Social Science, Health \& Medicine

Master of Arts: Bioethics \& Society

2nd September 2015 


\title{
"Meditations on Drugs": A Buddhist Ethical Approach To Pharmaceutical Cognitive Enhancement
}

\begin{abstract}
Purpose: The purpose of this project is to explore the moral permissibility of pharmaceutical cognitive enhancement through the lens of Buddhist ethics and to examine what relevance Buddhist ethics can bring to the western discourse of pharmaceutical cognitive enhancement. This will also help to bring about a more global perspective towards this particular bioethical issue.
\end{abstract}

Methodology: This project has a two-pronged methodology: a literature review of the western bioethical discourse on pharmaceutical cognitive enhancement and a qualitative analysis of the participants, Buddhist monks and nuns, who were interviewed.

Results: The moral framework that emerged from the interviews coincided with the framework that was derived from the literature review. Buddhists also seemed to prefer alternative forms of cognitive enhancement such as mediation and education to the biomedical or pharmaceutical. However, they saw little inherently wrong with the pharmaceuticals themselves so long as they are used in moderation and all other contexts are considered.

Conclusions: What this project brings to the discussion of the bioethical issue of pharmaceutical cognitive enhancement is a consideration for another alternative form of enhancement, primarily meditation. It also brings in a new moral framework that is not found within the West. By considering ethical issues from a Buddhist lens this develops a more global perspective on the issue, which is certainly needed, as it is possible that pharmaceutical cognitive enhancement will likely not remain as a bioethical issue that is only found in the West. 


\section{Dedication}

This dissertation is dedicated to the Buddhist communities of London and Oxford, whose compassion and wisdom are what made this body of work a possibility.

I certify that the work submitted herewith is my own and that I have duly acknowledged any quotation from the published or unpublished work of other persons. 
Table of Contents

$\begin{array}{lr}\text { Chapter 1: Introduction } & 1\end{array}$

Chapter 2: Methodology 5

2.1 Introduction $\quad 5$

2.2 Ethics Approval 6

2.3 Conducting a Literature Review 6

$\begin{array}{ll}2.4 \text { Sampling Strategy } & 7\end{array}$

2.5 Participant Interviews $\quad 8$

2.6 Coding \& Analysis 9

2.7 Limitations $\quad 11$

Chapter 3: The Western Bioethical Discourse

on Pharmaceutical Cognitive Enhancement $\quad 12$

3.1 Introduction 12

3.2 Definitions of Enhancement $\quad 15$

3.3 Biomedical Research in Cognitive Enhancement $\quad 15$

3.4 Cognitive Enhancement in University Students 16

3.5 Buddhist Forms of Cognitive Enhancement 17

3.6 The Three Paradigms $\quad 18$

3.6.1 The Prescription Drug Abuse Paradigm 19

3.6.2 The Cognitive Enhancement Paradigm 19

3.6.3 The Lifestyle Choice Paradigm $\quad \mathbf{2 1}$

3.7 Innovation Equivocation $\quad 22$

3.8 Fair Access to PCE

3.9 Cheating in Academia and Sport $\quad 24$

3.10 Freedom From Coercion $\quad 25$

3.11 Conclusion $\quad 27$

Chapter 4: An Introduction to Buddhist Ethics 29

4.1 Introduction $\quad 29$

$\begin{array}{ll}\text { 4.2 The Dharma } & 30\end{array}$

4.3 Karma \& Rebirth $\quad 31$

4.4 The Four Noble Truths $\quad 33$

4.5 The Noble Eightfold Path $\quad 34$

4.6 The Five Precepts $\quad 36$

$\begin{array}{ll}4.7 \text { Conclusion } & 38\end{array}$

Chapter 5: Results and Discussion of a Qualitative

Analysis of Buddhist Monastics' perspectives on PCE 39

$\begin{array}{ll}5.1 \text { Introduction } & 39\end{array}$

5.2 Buddhist Ethics $\quad 39$

5.2.1 The Noble Eightfold Path $\quad \mathbf{4 1}$

5.2.2 Meditation $\quad \mathbf{4 4}$

5.2.3 The Fifth Precept $\quad \mathbf{4 9}$

5.3 Ethics of PCE

5.3.1 University Students

5.3.2 Pharmaceutical Companies $\quad \mathbf{5 4}$ 
Chapter 6: Conclusion and Implications for Bioethics

Appendix A: Research Ethics Committee Approval Letter 


\section{Chapter 1 \\ Introduction}

"Happy is the birth of a Buddha, happy is the teaching of Dhamma, happy is the harmony of his followers, happy is the life of those who live in harmony." - The

Dhammapada,

The following project will explore the moral use of pharmaceutical cognitive enhancement (PCE) (as defined below) through the framework of Buddhist ethics. It will also explore and seek to understand how a Buddhist ethical lens could expand the western bioethical discourse on PCE (see chapter 3 for a discussion). Here, a Buddhist ethical framework is built and compared to the views that are currently found in the western bioethical discourse on PCE. Pharmaceutical cognitive enhancement is the effort and ability to better or "enhance" an individual's cognitive capabilities and capacities through the nonmedical use of pharmaceuticals. It should be noted that this dissertation is not concerned with the use of PCE for therapeutic purposes. I will discuss the distinction between therapy and enhancement in chapter 3 as well as the definition of "enhancement". However for the current purposes the definition of cognitive enhancement will be known as an increase in the capabilities and capacities of cognitive function.

Under the definition of cognitive enhancement that is being used in this research, a form of Buddhist practice can be considered as cognitive enhancement. It is well known that meditation is integral to the Buddhist way of life and meditation here can be considered as a form of cognitive enhancement. This is not because the intended purpose of meditation is to become an enlightened being like the Buddha. Rather, it is because there are certain types of 
meditation that do increase certain cognitive functions such as mindfulness, focus, energy, and alertness.

This project is only concerned for otherwise healthy individuals who intend to use pharmaceuticals in order to enhance their cognitive capabilities and capacities. It should also be noted that the framework for ethical analysis comes from a combination of background literature and analysis of views found in Buddhist monastic communities throughout Oxford and the Greater London area. Also, it is important to understand PCE through a Buddhist lens so as to create a more inclusive ethical environment and discussion for the use proper use thereof.

As globalization continues, more and more people and societies are beginning to interact like never before. Ideas can be spread across the globe with a press of a button and collaborations in research are very common, especially in medical research. Research teams from all over the world can work together on any medical issue and strive to solve today's world dilemmas. While the advantages of global collaboration on medical research are outstanding, it raises the question of what ethical standards should be considered when research is being conducted, or even when policies are being shaped?

Global ethics, according to the organization "Globalethics.net", "is an inclusive approach to common binding values, guiding principles, personal attitudes and common actions across cultures, religions, political and economic systems and ideologies." (Cisneros, 2011). Global ethics points to the universality of specific values that are cross culturally found in societies from around the world and believes that these universal values can be guiding principles for ethical practices. 
One important reason why global ethics developed was to keep ethical discussions from having certain myopic perspectives that do not include considerations from other cultures. Global organizations like "Globalethics.net" bring individuals from all over the world together to determine a proper methodology to help shared values among societies flourish. Many of these individuals believe that religion could be a helpful guide and contribute to ethical discussions; while at the same time keeping in mind that religion in of itself is a problem. But many of the conflicts that arise from these discussions have to do with the differences between the religions themselves.

There are a few reasons to why considering Buddhist ethics for the issue of PCE can be beneficial towards the discussion of its moral permissibility. First, there are over 150,000 practicing Buddhists in the UK alone (Ruth, 2005). Many of who would go to Buddhist temples or centres to seek advice from the monks on certain issues. Understanding how Buddhists view the issue of PCE will help bring in a population of individuals that would otherwise be marginalized. Secondly, in order to avoid ethical imperialism (a code of conduct or attitude that is imposed upon another community) that would stem from ethical relativism it is important to understand ethics from the Buddhist perspective (Small, 2008). This will allow us to come across ethical principles and values that are similar to what can be found elsewhere in the world. It will allow us to weed out specific western values and focus more on the common values found between the East and West. However, this should not mean that we ought to ignore the unique values and considerations from Buddhist ethics, as they too might have some significance towards how the community considers ethical actions (Turner, 2004; Angell, 1988). 
It should also be noted that bioethics has weighed in on alternative forms of medicine and practices (Turner 2004). There is a growing resurgence of utilizing alternative medicines in certain cases. For instance, mindfulness meditation practices are now being used for individuals who suffer from PTSD (Polusny et al., 2015). Because of this growing incorporation of an alternative eastern practice in the West, it is therefore important to consider how the practitioners of mindfulness meditation (i.e. Buddhists) morally perceive the use of pharmaceuticals for the purposes of cognitive enhancement.

In conclusion, the project aims to further the discussion in the bioethical community on the subject of PCE by exploring Buddhist ethics and to reveal what Buddhists can offer to the debate. In order to avoid ethical imperialism and to generate a more global view of ethics and a more global view of PCE it is important to understand ethical concerns from both the West and East. It is not enough to only consider the values that are found in western societies. As such Buddhist ethics will offer an insight into eastern values and reduce the risk of marginalizing populations of people in the West who have an Eastern heritage. 


\section{Chapter 2 \\ Methodology}

"Let him live in love. Let his work be well done. Then in a fullness of joy he will see the end of sorrow." - The Dhammapada

\subsection{Introduction}

The overall aim of the study is to understand how a Buddhist ethical lens could expand upon the current bioethical discourse on PCE. The methodology of this dissertation is two fold: first, the use of a literature review of the western discourse on PCE and of Buddhist ethics, and second, a qualitative analysis of semi-structured interviews conducted with Buddhist monks and nuns. As such, Buddhist monks and nuns throughout London and Oxford were interviewed and considered as authorities on Buddhist ethics and meditation. It is important to consider the monks and nuns as authorities on meditation as it is a form of cognitive enhancement and it is an integral part towards their religious practice. This chapter considers the parameters of the study conducted and how they were achieved.

\subsection{Ethics Approval}

The ethics of conducting this project was approved by King's College London Research Ethics Committee via a minimal risk application and was granted approval on 23/03/2015 (Appendix A). This project was a pilot project for the minimal risk application process at King's College London. While PCE and Buddhist ethics are not necessarily sensitive topics it is important to still be respectful of the views of the Buddhists on the issue. Great care was taken to adhere to the religious customs of the Buddhists so as not to offend them. This means respecting their holy places and objects. Such customs as taking shoes off 
at the door of the sangha or temple, not touching the Buddhists (such as shaking hands), and bowing were adhered to closely. No incentives were offered for participation in the study.

All but one participant were notified ahead of time of the interview and were given an information sheet (Appendix B) and consent form (Appendix C) about the project. All participants consented to the interviews of their own volition. The one participant that was not notified previously of the interview read the information sheet and consent forms before consenting to being interviewed. Additionally, contact information of both supervisors as well as the researcher was provided. The consent form made clear that the participants were allowed to withdraw from the study at anytime up until the point of transcription. It also thoroughly explained that the data from the project would be held in accordance with the UK Data Protection Act of 1998.

The participants who did not wish to be fully identified in the study were assigned a code letter to protect their confidentiality. All participant records were stored on an external hard drive with an encrypted password for protection. The audio recordings were sent to a transcription service, Transcription Divas, and transcribed for a fee. Only the code letters of individuals were given and all personal information in recording was deleted before sending the audio recordings. After transcription, the audio recordings of the interviews were destroyed.

\subsection{Conducting a Literature Review}

This section concerns how the literature review of this dissertation was conducted and what was considered important in constructing the background 
information on both the western discourse of PCE in bioethics and the framework of Buddhist ethics. Key search words and phrases such as "Buddhist Bioethics", "Buddhist ethics", “Buddhism", “Global ethics", "Pharmaceutical cognitive enhancement", "PCE competition", "University students and PCE" and "Buddhist cognitive enhancement" were used in search engines and databases in order to help generate the ethical framework as well as to help present western views of PCE. The search engines that were used were; Google scholar, King's College London Library Catalogue, Taylor \& Francis Online, and WorldCat.

My correspondence with Kate Crosby of King's College London was integral for conducting the research for this project as she suggested where to begin the research and introduced Buddhist ideas. She also introduced me to two participants of the study, with whom I later spoke to individually as Kate Crosby was not their gatekeeper. I also corresponded with Damien Keown, who is an authority on Buddhist ethics for assistance and advice on the research.

\subsection{Sampling Strategy}

Judgemental sampling was the sampling method used to recruit participants for this project (Stenhouse, 2013). Participants were to be ordained monks or nuns and must have an adequate understanding of meditation and, more importantly, Buddhist ethics. All of the monastics that were interviewed have had at least a decade of experience in practicing Buddhism and were well versed in its ethics.

Ideally, the sample population would include an equal number of monastics from different Buddhist cultural backgrounds. While an equal number of Buddhists from different traditions was not achieved, the diversity of different 
traditions still existed within the sample populations. Buddhists from the Mahayana (found in East Asia), Vajravana (Tibetan), and Theravada (South East Asia) traditions participated in the study. The participants interviewed ranged in experience. Some were higher ranking monastics such as Lamas or Abbots while others were in entry-level positions. Those who participated in the project were then asked if they knew of other monastics or communities that would be willing to participate in the research and are qualified to do so.

\subsection{Participant Interviews}

The interviews conducted with the participants were semi-structured in nature. All interviews were conducted in person at a place of the participant's choosing. This usually involved conducting the interviews at the temples, meditation centres, or sanghas where the Buddhist monastics reside. As such, a great amount of care and respect for the participants' dwelling places and religious or revered spaces and objects was practiced diligently. The interviews were conducted at a convenient time of the participants involved and lasted anywhere from 30 to 60 minutes depending on the available time allowed. All interviews were audio recorded on a handheld dictaphone. A topic guide of questions pertaining to particular subject matter was loosely followed (Appendix D). Occasionally, some topics of discussion came up with some participants that did not come up in others.

The topic guide is meant to guide the conversation between the researcher and the participant. It allows for in depth conversation on specific issues and also allows slight freedoms to the topics of conversation. The topic guide for this project had three key areas of discussion: Meditation, Buddhist 
Ethics, and PCE. Not all of the questions can always be asked from the topic guide so importance was stressed on the issues of Buddhist ethics and PCE. Meditation was important to add in the discussion because it is a form of cognitive enhancement that is found in Buddhism and possible similarities between meditation and PCE could arise. This may lead to more in depth conversations and views that the Buddhists will have on the permissible use of PCE. Some field notes such as laughter, inquisitiveness, and other emotions were made during the interviews.

\subsection{Coding \& Analysis}

The method of coding and analysis that is adopted here in this project was a method that was developed by Philip Burnard (1991) who adapted his method of analysis and coding from the "grounded theory" approach of Glaser and Strauss (1967). The purpose of using grounded theory in this project is two fold: to generate hypotheses on the nature of Buddhist ethics and how Buddhists will consider the moral use of PCE, and to confirm or nullify pre-existing understandings of Buddhist ethics. Hence, grounded theory utilizes both inductive and deductive reasoning. The coding of the transcripts was done by hand. All eight interviews were coded in the same manner. Codes were vast and diverse throughout the interviews. The aim of this is to become more immersed with the data and to become more aware of the Buddhist "frame of reference" (Burnard, 1991; Rogers, 1951). After the initial immersive coding, the transcripts were read through again and headings were written down to help describe the aspects of the content. This is where the concepts of the content begin to emerge. 
The codes were changed, altered and grouped as more patterns emerged. Collapsing and combining certain concepts generated broader categories.

The codes and concepts were finally placed into six major categories:

- The Noble Eightfold Path

- Meditation

- The Fifth Precept

- University Students

- Pharmaceutical Companies

- Analogous of Sport - Competition and Cheating

Some of these categories may contain concepts that are made up of multiple codes. Some of the codes may be able to belong to multiple categories do to the nature of topic having interconnected ideas. The codes were arranged in this way so as to better perform an analysis of PCE from the standpoint of Buddhist ethics. Ultimately two themes came from the categories: A Buddhist Ethical Framework and Ethics of PCE.

A mentioned previously, the themes are comprised of categories which are in turn comprised of concepts that were generated from codes of the data. For instance, the category of "Analogous of Sport" can be comprise of key concepts, such as competition and cheating, that emerged from codes. Codes such as feelings and attitudes towards competition as well as field notes delineating facial expressions, hand gestures, and other body language that would indicate attitude or modes of thought were combined to make the concept. This was repeated with the concept of cheating. The concepts seemed to fit well together as often times the discussion of competition lead to a discussion of cheating (or vice versa) in the interviews. Most of the time these discussions took place in the context of analysing the moral permissibility of performance enhancing drugs in sport, something the participants found to be analogous to 
the use of PCE in an academic setting. Hence, the two concepts could be placed under the same category of Analogous of Sport. These sorts of connections were sought for in the same manner when analysing the data for other concepts and categories.

\subsection{Limitations}

One of the limitations of the study is the population sample size. Only eight monastics were interviewed in order to construct the ethical framework and come to a moral conclusion as well as to assert their relevance to the bioethical discussion. While more participants would be desirable it may be that the current number of participants and data collected is not enough to reach a final conclusion. Another limitation is that only monks from London or Oxford could be considered or interviewed due to logistical reasons.

It may also be the case that the general Buddhist framework constructed may not be representative of the entire Buddhist population or sects. The majority of the participants interviewed were of the Theravada Buddhist tradition while Tibetan and Mahayana traditions of Buddhism had fewer participants and thus less of an overall say. Specifically 4 Theravada Buddhists, 2 Tibetan Buddhists, 1 Chinese Buddhist and 1 Zen Buddhist participated in the study. 


\section{Chapter 3 \\ The Western Bioethical Discourse on Pharmaceutical Cognitive Enhancement}

"What we are today comes from our thoughts of yesterday, and our present thoughts build our life of tomorrow: our life is the creation of our mind."

- The Dhammapada

\subsection{Introduction}

The purpose of this chapter is to present a rough outline of the western bioethical discourse that can be currently found on PCE. Here I will consider the different definitions of enhancement and how they shape the way PCE is viewed. I will also consider the biomedical history that is associated with PCE (mostly the biomedical history of methylphenidate) as well as Buddhist forms of cognitive enhancement. Further, considerations on the different western paradigms of thought when it comes of PCE will be addressed as Buddhists may fall into one these different paradigms. Finally, in this chapter I will address a few of the arguments that are found (both for and against) on the use of PCE, the example of university students who use PCE in order to boost their academic performance will be the centrepiece for understanding these arguments.

\subsection{Definitions of Enhancement}

In order to proceed with the project at hand it is necessary to establish a definition as to what is meant by "enhancement". According to Silvia Camporesi (2014), there are different meanings to the term "enhancement" and different ways people tend to approach the term. The first, and most simplistic is taking the implicit approach in its definition. When someone uses the term "enhancement" without giving some sort of definition then that person is 
assuming that everyone knows its meaning through common sense. The obvious drawbacks here are the lack of understanding the complexity of enhancement itself and not understanding the constant change in social and political values that could influence the meaning of the word over time.

The second approach is to consider enhancement as improvements of human capacities and abilities. According to Julian Savulescu (2006) this is a functionalist approach as the definition is only concerned with increasing mental capabilities beyond the normal species functioning or statistical species function. It can also be considered as the improvement of previous capabilities. This definition is widely used throughout the bioethical literature. While this may seem somewhat intuitive, the definition has a problem when it comes to assessing what the normal species function is depending on the ability and depends upon such notions as "health" and "disease". It also has to deal with figuring out what is considered to be healthy enhancement and what may not necessarily be enhancement. For instance, high-functioning autistic can cognitively preform above and beyond what could be considered as normal species functioning in cognition. Yet high-functioning autistics have difficulties in other aspects of human functioning such as social interaction. Under the current definition it is unclear whether or not high-functioning autistics are enhanced human beings. Often times they are described as individuals who have disabilities rather than "super-abilities" (Coucoucvanis, 2005).

The third approach to enhancement is to consider enhancement as an increase in wellbeing. This approach defines enhancement as an improvement in an individual's wellbeing or welfare and is not commonly seen in scholarly research (Camporesi, 2010). The improvements are changes within a person 
(either biological or psychological) that are considered to be good for that person. Here what changes are considered to be good depend upon the what values are being promoted (Camporesi, 2010; Savulescu, 2006). While this definition does not have the same problems as the capabilities approach, it does have problems of its own. For example, the definition is value laden and is based on controversial concepts such as: wellbeing, welfare, and human flourishing (Camporesi, 2010).

The final approach to enhancement is to use the distinction between therapy and enhancement in order to gain and understanding of the definition. The distinction between therapy and enhancement in this notion is meant to be a "moral boundary line" between the permissible and impermissible uses of the biomedical technologies (Camporesi, 2010). This approach must have other clearly defined terms in order to function properly. Such terms as "health" and "disease" need to be addressed before the boundary line between therapy and enhancement can be distinguished. Such terms are a hot bed of controversy in academia. Medicine that is designed for health prevention may even fall under the enhancement category (Camporesi, 2010).

For the purposes of this project the more functionalist approach towards enhancement will be considered when discussing background information and arguments. One reason being is that the definition is more widely used in bioethics literature than the wellbeing or implicit approaches. Another reason is that an implicit assumption on the definition could lead to wider misinterpretation of the data and for the monks who will be interviewed. The therapy and enhancement distinction will not be used since we are solely focusing on enhancement ethics rather than therapy, but it is important to 
understand the difference between the two. However, the Buddhist monastics that will be interviewed may not subscribe to the same definition of enhancement that is adopted here, hence the importance of understanding the distinctions in the definitions.

\subsection{Biomedical Research in Cognitive Enhancement}

The vast majority of the current research that is being conducted on pharmaceuticals for the mind is for therapeutic purposes. Most of the pharmaceuticals that are being developed are meant to treat patients with medical psychiatric disorders. Examples such as Attention Deficit Hyperactivity Disorder (ADHD), Alzheimer's disease, and schizophrenia are the most common examples of this. And so, pharmaceuticals such as methylphenidate (a.k.a. Ritalin), donepezil, and modafinil were developed to help alleviate the symptoms of these disorders. However modafinil was developed to ease symptoms of narcolepsy and sleep apnoea.

This particular project will focus on the pharmaceutical of methylphenidate, which is commonly prescribed to individuals with ADHD. This is in part because methylphenidate is perhaps the most controversial and talked about pharmaceutical. University students have notoriously been using methylphenidate to increase their performance in their academics. Methylphenidate is designed to help improve cognitive functions such as focus and working memory by affecting the catecholamine system (the same system that includes neurotransmitters such as norepinephrine and dopamine) (Greely et al., 2008; Sahakian \& Morein-Zamir, 2010). It blocks or inhibits the reuptake of the neurotransmitters norepinephrine and dopamine from the synaptic 
junctions (Sahakian \& Morein-Zamir, 2010). This causes an increase in spatial working memory and quicker completion of objective tasks. There is no evidence to support that methylphenidate helps to improve any kind of creative function.

ADHD is a heritable neuropsychiatric disorder and is estimated to effect 3 to $7 \%$ of children around the world. Under the Diagnostic and Statistical Manual (DSM) criteria, about 7\% of university students are diagnosed with ADHD. The annual cost of treatment for individuals with ADHD in the USA in 2000 was around $\$ 42.5$ billion (Pelham et al, 2007 as cited in Sahakian \& Morein-Zamir).

\subsection{Cognitive Enhancement in University Students}

A large focus of this study is centred on the ethical use of PCE in university students. The bioethics community commonly explores this particular example of PCE and there are often concerns of competition, freedom, health risks (specifically long-term), egalitarianism and cheating. In the United States studies show that $16 \%$ of students use some sort of cognitive stimulant and nearly $8 \%$ have used prescription drugs illegally for cognitive enhancement (Sahakain and Morein-Zamir, 2011; McCabe et al., 2005). On some university campuses $25 \%$ of the student population have used prescription drugs to enhance their performance (Greenly et al, 2008; Mahar, 2008). Other studies show that these numbers are growing, not only in the USA but in the United Kingdom as well (Singh, 2014).

Typically university students will use pharmaceuticals associated with the treatment of ADHD such as methylphenidate or other forms of amphetamines. Methylphenidate has three properties that are desirable to students; it reduces the need for sleep, heightens an individual's concentration, and it is thought that 
it can effect the reward system of the brain by controlling the levels of neurotransmitters. These tend to be the reasons why students want to use methylphenidate for non-medical purposes.

University students obtain the pharmaceutical from individuals to whom physicians have prescribed the medication. The selling or trading of prescription pharmaceuticals is an illegal act and punishable by the states or U.S. federal government with fines or imprisonment, let alone possible expulsion form the university. Often times the use of methylphenidate in academia is compared to the use of steroids in sport and sometimes they do have the same legal status. Some believe that the regulation and control of PCE should be the same as steroids in sport. There are inherent dangers of obtaining drugs from the black market and these safety concerns (or there lack of) are of huge concern. These are just a few reasons why bioethicists are reconsidering the possible permissible uses of PCE. Arguments, both for and against, on the use of PCE in university students will be explored further in the next chapter.

\subsection{Buddhist Forms of Cognitive Enhancement}

There are two examples of meditation practice that have been known to assist mental faculties; samatha and vipasyana (Fenton, 2009; Saddhatissa, 2003). Samatha meditation is also known as calming meditation. This form of meditation has been known to help with focus and concentration. The technique involves focusing on one's own breath. With consistent practice on the observation of one's own breath a sense of calm is often felt as well as increase in focus (Fenton 2009; Saddhatissa, 2003). Vipasyana meditation focuses more on the personal phenomenological experiences and tries to understand the nature 
of those experiences. One technique of this meditation is to try and "observe without judgement" one's ever-changing phenomenological experience (or one's own consciousness). Based on the observations found through this mediation a person is said to be able to better understand the nature of reality (Fenton 2009; Saddhatissa, 2003). This is a form of mindfulness meditation and allows a person, with practice, to be more mindful of her surroundings as well as her own feelings. Bearing this in mind, it may be the case that Buddhists are well equipped with unique knowledge of cognitive enhancement that is not typically found in the West and try to answer moral questions on the use of PCE.

\subsection{The Three Paradigms}

Much of the current debate on PCE is derived from previous notions such as competition, drug abuse, public health, egalitarianism, and freedom. These ideas are ever present in the ethical debate. How people view these aspects will influence how they view what the proper role is (if any) for PCE and other forms of cognitive enhancement. How the use of PCE is currently considered under different paradigms is paramount to understanding what relevant and significant insights that Buddhists can offer. For example, it may be the case that Buddhists would prefer to view PCE under the light of public health rather than that of competition. They may even have other perspectives to consider that are not currently found within debates in the West.

According to Racine and Forlini (2010), there are three distinct paradigms in the discussion of PCE: Prescription Drug Abuse, Cognitive Enhancement, and Lifestyle Choice. Each paradigm is unique and can found in the neuroethical debates over the use of PCE. The fact that there are distinct 
paradigms shows that there is no major consensus on the non-medical use of pharmaceuticals (Racine \& Forlini, 2010). However all the paradigms are important to understand so that future discussions do not end up in a myopia of a single paradigm. Each paradigm has its own valid considerations and concerns that should be addressed.

\subsubsection{The Prescription Drug Abuse Paradigm}

Many of the public health studies done on the non-medical use of prescription pharmaceutical stimulants are centred on the terms "prescription drug abuse" (Lucke, 2013; Racine \& Forlini, 2010). In this paradigm the main concerns are centred on individual and societal health, the focus here is on the health and addiction risks involved in the practice of using pharmaceuticals for non-medical purposes. However according Racine and Forlini (2010), the paradigm has certain "drawbacks" which include a harsh description of pharmaceutical use as drug abuse and lacking a kind of context of certain scenarios. One such example is while there is indeed a black market for certain pharmaceuticals such as methylphenidate, university students will often claim and present false symptoms of ADHD to physicians in order to obtain a prescription. The paradigm could also not reflect the current public attitudes towards the non-medical use of pharmaceuticals. It may not even represent the ethical uncertainties that are found within the bioethical communities because its language and stance against the use of pharmaceuticals is too strong (Racine \& Forlini, 2010).

\subsubsection{The Cognitive Enhancement Paradigm}


In the bioethics literature there are mixed feelings towards the use of PCE. Even the language that is used is different from what is found in the drug abuse paradigm, instead of considering the use of pharmaceuticals as prescription drug abuse, it is considered as cognitive enhancement. This paradigm focuses on particular ideas such as identity, autonomy, and what it means to practice good medicine. Here, identity is usually considered as a constant meaning that some person or individual would be the same regardless of using a pharmaceutical to cognitively enhance or not. Autonomy is the ability and right to self-govern, the ability to make clear and definitive choices or decisions for one's self. It also is in line with notions of freedom; in this case it may be freedom from coercion, which is to say that that one is free from being forced or coerced into using cognitively enhancing pharmaceuticals because of aspects like intense competition that creates the necessity for the use of PCE in order to keep up with one's competitors. Finally, the paradigm considers that what it means to practice good medicine is to both treat and enhance patients' biological and psychological functions.

More on these arguments will be explained below. But it should also be noted that this particular paradigm does not focus on certain aspects of cognitive enhancement. Mostly it ignores "functional aspects" that could help to bring about an ethical use of cognitively enhancing pharmaceuticals such as long-term medical effects or the potential for addiction. The paradigm will usually consider the ethical dilemmas of cognitive enhancement while taking for granted that it is safe, effective, and legal to use. Because of this, the debate that is found in the bioethical community may not be in line with the perspectives that are found in 
the public health sector (which tend to adhere more towards the drug abuse paradigm).

\subsubsection{The Lifestyle Choice Paradigm}

There is a greater emphasis found in the public sector for the "lifestyle choice" paradigm. This particular paradigm too alters the language of the ethical debate by naming prescription drugs as "lifestyle drugs" (Lucke, 2012). This is a rather optimistic outlook on the use of pharmaceuticals as the paradigm encourages individuals to reach their full potential through the use of such lifestyle drugs. One such example is found within the media, the primary place where the paradigm can be found. The non-medical uses of stimulants such as methylphenidate are called "smart drugs" and are often compared with study aids or caffeine pills. There are concerns associated with this public and media paradigm. Outside of the medical community, there is a growing acceptance of these pharmaceuticals and portrayals of the safety and efficacy of these drugs can be misleading. Oftentimes the unknown risks that are associated with the pharmaceuticals are downplayed. This makes the paradigm the most difficult to grapple with in the bioethical debate as it has altered the role of pharmaceuticals from treatment of illness to achieving a personal goal (Lucke 2012; Racine \& Forlini, 2010).

It is important to understand these different paradigms of thought as the Buddhists who will be interviewed may subscribe to a specific paradigm. It could even be the case that the Buddhists have never considered these different paradigms, as their experience with PCE would be minimal. They may not even 
believe that mediation, what is here considered a form of cognitive enhancement, should fall under the cognitive enhancement paradigm.

\subsection{Innovation Equivocation}

The example of university students who use PCE was briefly considered above but will continue to be explored through the notion of innovation and competition. Innovation has always been a part of humanity, pushing the species forward towards a better future. New and improved techniques in technology are always being created and implemented. This is true even when it comes to cognitive enhancement. Education is considered as a form of cognitive enhancement. Written language, the printing press, and eventually the Internet were all ways that have improved upon our cognitive capacities and capabilities. It also comes as no surprise that there are added mental benefits that come from having a proper nutritious diet, getting enough exercise, and sleeping regularly; and all of these methods can be considered as cognitively enhancing. So why then should pharmaceuticals not be perceived as part of these same categories of cognitive enhancement? After all, the pharmaceuticals themselves are manmade innovations as much as the Internet and are just as invasive as a proper diet would be.

Greely and his colleagues (2008) are proponents of this categorical equivocation and believe that PCE is just another innovation of humanity that will benefit us in much the same way as education and the Internet have. All these ways of cognitive enhancement are innovative ways that humanity has created in order to make life better and easier for ourselves. But as Greely suggests, not all forms of cognitive enhancement are equivalent and the 
differences in means ought to be considered. Some means of enhancement require more effort or work than others. Meditation, for instance, requires some practice before many of the benefits blossom; whereas the effects or results of the pharmaceutical are more immediate. While the pharmaceuticals are as invasive as changing a diet would be, it must be said that this means PCE is more invasive than education or meditation. The drugs themselves require little effort and are invasive but these are not adequate enough reasons to ban them altogether, since they are equivalent to the innovation of the other forms of technology in different ways.

\subsection{Fair Access to PCE}

Another way bioethicists argue in favour of PCE is by claiming that this form of enhancement is part of healthy competition, but only if there is equal access to the pharmaceuticals (Cakic, 2009). This slightly lends itself to the innovation argument because PCE is an innovative way to cognitively enhance and can help bring about healthier competition provided equal access. The key here is equal and fair access. In much the same way as the Internet, access to these pharmaceuticals is not equally distributed amongst populations.

Greely (2008) and John Harris (2010; 2008) have considered the possibility of unfair competition through unfair access. It would be just as unfair to allow certain children in the classroom a calculator on a maths exam while other children do not have access to one. But, Greely and Harris would point out, there are already unfair advantages found within the educational system. Some children have access to private tutors or have more funding for education than 
other children. These sorts of resources give some children an advantage over others but no one bands the practices of private tutoring.

But what makes access to PCEs unfair is in part from what they can do. For instance, does PCE improve the uptake and retention of information and are these effects long lasting? If so, then this could be considered as fair use because the exam is providing an accurate measure of the intelligence found in the individual. This is in much the same way as having assistance from a private tutor; while it may seem unfair or non-egalitarian there is nothing necessarily morally wrong with the practice itself. Rather the problem lies with how to equally distribute private tutors. If on the other hand, the pharmaceuticals merely boosted exam performance then it seems like it would be unfair to use them since the results would not accurately reflect the competency found in the students. This might be the equivalent of having an unauthorized "cheat sheet" for the exam. This would need to be addressed before allowing the use of PCE for academic performance purposes. Opponents of PCE would point out that the scientific evidence seems to support the latter scenario and the former. Hence, why many people believe that students who use PCE for academic performance are cheating.

\subsection{Cheating in Academia and Sport}

Competition concerns then take on the form of cheating. This is perhaps a large concern for universities, whose current views on the use of PCE have mostly been a combination of either strict or no-tolerance policies. It should be noted that this is also in part because laws are strict about the acquisition of pharmaceuticals. The worry is that the use of PCE will lead to some student to 
have an unfair advantage over their competition. This leads back to the previous section of fair access. The worry also stems from the uncertainty of what the pharmaceuticals can actually do. A comparison is often made between students who use PCE and professional sport, where the use of performance enhancing steroids is highly regulated and forbidden from use unless with a prescription from a doctor. Under the current World Anit-Doping Agency (WADA) guidelines and regulations, even mere possession of any illicit biomedical material is a punishable offense and the athlete is considered to be doping, even though the athlete may not have anything in her system (Cakic, 2009; Partridge et al, 2012).

Another reason why some may view the use of PCEs as cheating is because it is simply against the rules. If a person is breaking the rules while taking an exam then that person is considered cheating. This is the same sort of criteria that WADA uses in their considerations on cases that are brought before them. The common objection to this argument is to say that if the only reason why the use of PCEs is considered cheating is because it breaks the rules of the exam (or sport in the case of WADA), then the answer to the problem is to simply change the rules to allow the use of PCEs. If the use of PCEs is allowed and does not break the rules then it is therefore not considered to be cheating and thus not impermissible.

\subsection{Freedom from Coercion}

Suppose that the previous line of reasoning does get through to legislation, universities, and WADA. The ban on PCE is then lifted and nonmedical use of PCE is permitted. There are concerns in doing this. One such concern is that it may be to indirect coercion. Suppose that after the ban on PCE 
is lifted and universe and then allows students to use PCE for academic exam. Some students who have the means to do so utilise PCE in order to boost their academic performance. However there are listings to do not have the means to use PCE, they may lack the funding resources that more rich individuals have. The worry is that this will create a super elite class of individuals who have both money and intelligence while at the same time creating in class individuals who do not have money and who are less intelligent. Even if it does not go to this extreme, it would create fewer opportunities for individuals from poor socioeconomic backgrounds, making the society less egalitarian.

The counterargument to this would be to make the pharmaceuticals more affordable so that the maximum number of individuals may be able to have access to the pharmaceuticals. A policy may take it one step further and provide all students with free PCEs, in much the same way a university would provide students with computers for exams (Greely et al., 2008). That way, when students go to take the exam more students will be using the biotechnology making it egalitarian once again. While making PCE affordable to all may quell egalitarian concerns, there are still concerns raised over the matter of autonomy or cognitive liberty (Sententia, 2004). In order to keep up with students who are using PCE on exams other students who may not be using PCE will feel pressured into using a biotechnology that they are not comfortable using, thereby being indirectly coerced into doing so.

The other possible way to coerce a person into taking the PCE is through direct coercion. Some direct coercive methods are forceful. The most common example is patients who are viewed as harmful to themselves or others and are forced to take medications for the diagnosed psychiatric disorders. This is, of 
course, at great expensive of their personal and cognitive freedoms. While these cases are somewhat controversial they are typically viewed it as moral. But not all direct coercive methods are as forceful as this. They may take on the form of requirements for a job or for a university. It is compulsory for students to show their competency of a subject in some fashion, whether is be through examination or writing essays, like this dissertation for example. The question then arises is where universities should make it compulsory for students to take PCEs. Most would think that this is an over reach of control and is too much of an invasion of cognitive liberty or a person's autonomy. These examples show that there are trade offs between different concepts such as autonomy and egalitarianism. There must be a balance found between the two in order for PCE to be properly used.

\subsection{Conclusion}

This chapter has covered how there are different definitions to cognitive enhancement as well as the biomedical background from which cognitive enhancement emerged. It also covered two forms of Buddhist cognitive enhancement, which were two forms of meditation (samatha and vipasyana). These forms of meditation can be considered as alternative forms of enhancement from the pharmaceutical option to do so.

There is still a debate happening in the bioethics community about the proper role for PCE. The different paradigms of thought are a testament to the ambivalence that can be found in the literature toward the proper use of PCE. Depending on the lens of the paradigms used, the moral outcomes of PCE use may be different. It is important to understand these different paradigms as the 
Buddhists could fall into one of them, subscribe to a couple of them, or have a different paradigm altogether.

Fair and healthy competition has always been a great concern for bioethicists in the current debate. Maintaining healthy competition while at the same time moving towards a more egalitarian society is a difficult task. Fair access to the pharmaceuticals seems to be dependent on how effective the drugs are and the extent of their ability. There is always the possibly of systemic abuse of the drug where the rich are the only ones who could afford to use PCE. Possible policies would have to be implemented in order to prevent an intellectual gap between the socioeconomic classes.

Cheating has always been a concern for any university and they must do all they can to mitigate that possibility. Cheating in academia has been equivocated to cheating in sport. Some proponents of PCE view this as a false equivocation, while others hold the equivalence to be true and also believe that the drug regulations (as presented by WADA) in sport ought to be relaxed as well.

Notions of freedom and autonomy are also deeply held concepts in the West. Coercion to take pharmaceuticals, whether directly or indirectly is only reserved or specific instances in medicine. However, as seen previously, PCE makes it difficult to keep both autonomy and egalitarianism without making some sacrifices.

In the next chapter, necessary background knowledge of Buddhist ethics will be presented and explained so that the relevance of the Buddhist monastic views may be further seen. 


\section{Chapter 4 \\ An Introduction to Buddhist Ethics}

"He who does what should not be done and fails to do what should be done, who forgets the true aim of life and sinks into transient pleasures - he will one day envy the man who lives in high contemplation." - The Dhammapada

\subsection{Introduction}

In order to fully understand Buddhist ethics it is important to first understand the history of Buddhism and parts of the religion itself. The cultural history of Buddhism and its religious teachings will be an ever-present milieu in the ethical framework that will be built. Tradition and history are important values to the monastic communities and as such have considerable weight in ethical issues. Because of this high regard for tradition it is therefore important to understand the historical context of Buddhist ethics. Yet there are other concepts, such as compassion, that make Buddhism very appealing. Thus it is also important to learn key concepts of Buddhism, as they will interplay with the ethics involved. While this chapter is not dedicated towards the entire history of Buddhism, it will still provide key aspects of its history. It will also provide key concepts required to understand how a Buddhist ethical framework is built and applied.

Some credit must be given to Damien Keown before proceeding since much of his work is in the backdrop of this project. Keown $(2005,1995,1992)$ theorized that the framework of Buddhist ethics is a form of teleological virtue ethics. This means that Buddhists have a goal or an end that ought to be achieved (hence, teleological), which is the "fulfilment of human potential". This goal is to be achieved through the cultivation of Buddhist practices that are virtuous in nature (Keown, 1995, 1992). This then changes the character of the individual to 
the point that the individual is virtuous and flourishing. According to Keown, there are parallels between virtue ethics and Buddhist ethics. Virtue ethics can trace its origins back to Aristotle when he initially pondered questions such as "what does it mean to life a good life?" or "How should one live?". The modern day western version of virtue ethics, then, draws inspiration from Aristotle's ideas of virtue and character. Human flourishing, to Aristotle, is the way that individual ought to live, he called this notion "Eudaimonia" and it is when the virtuous person is happiest (Kraut, 2014). Keown $(2005,1995,1992)$ then draws this parallel to Buddhist ethics since Buddhists also believe that in order to achieve human flourishing a person must be virtuous. This flourishing to Buddhists is known as nirvana. This is the state that Siddhartha Gautama discovered when meditating and became "the awakened one" (the literal translation for the word "Buddha").

\subsection{The Dharma}

Part of the foundation for Buddhist ethics is in the idea of the Dharma. The noun Dharma has many different meanings; one meaning is "the ideal" or "that which is to be realized", this would become Buddha's teachings. The word is also known as something that could be equivalent to "natural law". This does not just include the natural laws of the universe as it includes forms of universal natural moral laws (Keown, 2005, 2004, 1995, 1992; Harvey 2000). These natural moral laws are typically objective in nature and were discovered, rather than invented, by the Buddha when he reached enlightenment (Keown 2005, Saddhatissa). The Dharma regulates every aspect of life from natural to 
behavioural phenomena. This can be considered in much the same way as the universe is regulated by natural laws.

The Buddha is said to have "turned the wheel of the Dharma" in his first sermon in a deer park in northern India when he spoke of enlightenment and of the way things are (Keown, 1995; Harvey, 2000). All the moralities, the four noble truths, the five precepts and the eightfold path can be considered as the Dharma. This interconnectedness between natural moral laws and virtues that can be found Buddhism is important to note and that the moral views found in Buddhism are not necessarily subjective in the eyes of Buddhists. To be a Buddhist is to live in accordance with the Dharma.

\subsection{Karma and Rebirth}

A portion of the Dharma is dedicated to the concept of karma. Karma is concerned with the ethical implications of the Dharma (Keown, 2005). At first glance it would seem that because of these two concepts Buddhism might be considered as consequentialist. That is to say that only the consequences matter when considering ethical issues. Often times Buddhists will use karma as an explanation for why certain actions are permissible and why others are not.

In order to receive good karma one must perform good actions. Should a person choose to perform an immoral act then that person will receive bad karma. Karma will not only affect a person's current life (ditthadhammavedaniya) but it will also affect a person's immediate rebirth (upapajjavedaniya) or even some eventual rebirth (aparapariyavendaniya) (Saddhatissa, 2003). A person in good karmic standing will have a favourable rebirth. The ultimate goal of these continuous rebirths is to eventually escape 
the cycle of rebirth and achieve nirvana. It is believed the Buddha was the first person to escape the cycle of rebirth and reach nirvana. However nirvana is seen more as a long-term goal, as something that will be achieved in future lifetimes and not this in this one. Lay people in good karmic standing usually hope for a favourable rebirth as another human being.

This is rather similar in concept with Christianity and a heavenly afterlife. Christians believe that if they do good deeds in this life, they will be rewarded in the afterlife. Should this then mean that karma is along the same lines as sinning? On the one hand, there are similarities between the two. Karma and sin involve how a person makes moral choices. They both invoke a causal relationship between acts done and the results of those actions. But there are differences between the two and they should not be considered equivalent. For example, a sin is a moral wrongdoing or an impermissible act. They affect a practitioner's relationship with God and cause the practitioner to fall out of God's favour or invoke the wrath of God.

Karma, in of itself, is not a moral act but culmination or sum of the deeds. In Hinduism (where the concept of Karma is also found) Karma does not affect the relationship between the practitioners and the Brahmin, the essential essence that is found within all things (Saddhatissa, 2003). Karma, in both Hinduism and Buddhism, only affects the person who has committed the deeds. Finally, the difference between sin and karma is that karma is the natural moral law that is found in the Dharma, universal moral law. It is an object that is found within the world itself. The results of the karmic acts that are committed are unavoidable. Whereas sin can be forgiven by God and taken away, thus sin is not 
necessarily consequential in nature nor does it lend itself to causal relationship or natural laws in much the same way as karma (Keown, 1995).

While Karma future rebirths are major considerations for Buddhist practitioners, they are not the only consideration for the Buddhist ethical framework. Much of what makes up the ethical framework of Buddhism is found within other portions of the Dharma such as the Four Noble Truths, the Noble Eightfold Path, and the Five Precepts.

\subsection{The Four Noble Truths}

The ultimate goal of Buddhism is to end suffering. Suffering (Dukkha) is not only physical pain; it consists of psychological pain as well. Even certain emotions such as anger are considered to be a form of suffering under the Buddhist view (Hughes, 2007). Suffering was the primary focus of the border and he discovered (in the same way as he discovered the Dharma) what is known as the Four Noble Truths. These truths are accepted by all Buddhists and propose that the causation of all suffering is desire.

The Four Noble Truths:

1. The phenomenological experience of life is unsatisfactory, frustrating and is an experience of suffering. - Dukkha

2. The reason for the unsatisfaction of life is because of craving or desire.

- Tanha

3. There exists a state in which there is an elimination of dukkha and desire - Nirvana

4. The path to achieving Nirvana is through the "middle way" and by adhering to the Noble Eightfold Path. 
Almost immediately, a possible framework can be considered as the foundation for Buddhist ethics. With such a focus on suffering it is easy to assume that Buddhist ethics may just as well be considered a form of utilitarianism or consequentialism just as Andrew Fenton (2009) has when he examines the issue of PCE. Consequentialism is a form of ethical theory where the primary concern of an act is based on the consequences of that act. As such the moral permissibility of an act is based solely on the consequences. Utilitarianism can be considered as a sub-category of consequentialism. What is morally best under this theory is an action that maximizes a utility, which is typically defined as well being (Driver, 2014). But a preliminary examination of Buddhist ethics paints a different picture as there is more to Buddhist ethics than just ending all suffering.

\subsection{The Noble Eightfold Path}

Another part of Buddhist ethics can be found in the fourth and last truth of the Four Noble Truths. By following the Noble Eightfold Path a person can eliminate all Dukkha or suffering. These eight paths were used by the Buddha to teach about the nature of phenomena (or reality). In Buddhism, the symbol for the Noble Eightfold Path is the wheel of dharma and has eight spokes. This is why when Buddha first taught the eightfold path is known as "the turning of the wheel of Dharma" (Keown, 2005; Fenton, 2009; Saddhatissa, 2003).

The Noble Eightfold Path:

1. Right View

2. Right Resolve

3. Right Speech 


\section{Right Action}

5. Right Livelihood

6. Right Effort

7. Right Mindfulness

8. Right Meditation

These are eight different paths are then placed under certain categories. Right View and Right Resolve are placed into the category of the insight (prajna). Right Speech, Right Action, and Right Livelihood are typically grouped together under the heading morality (sila). Finally Right Effort, Right Mindfulness, and Right Medication or all placed under the heading of meditation (samadhi). The word "Right" that comes before every path can be considered as an ideal or perfection (Keown, 2005, 1995; Harvey, 2013; Saddhatissa, 2003).

Already a different picture of Buddhist ethics begins to show. An entire portion of the eightfold path is dedicated to morality (sila). For Right Speech, if someone says something that will cause harm to another person, then do not say it, whether it is true or not. There is a proper time and place for certain things to be said. Right Action focuses on acts that are almost always considered wrong such as killing, stealing and sexual misconduct. Right Livelihood involves the business side of our lives and how a person makes a living. According to this path, practitioners are not allowed to earn a living that could result in harm towards other people. Participating in such nefarious businesses such as arms or drug dealing, prostitution, or any other business practices are designed to cause harm (Keown, 2005, 1995, 1992; Harvey, 2013; Hughes, 2007; Saddhatissa, 2003). 
In these cases for sila there is almost no room for exceptions, making them rather deontological in nature. But it must not be forgotten that all of these restrictions on speech and action are meant to reduce suffering. These paths are meant to be tools used to shape our personal characters and obtain nirvana. Much of what is discussed here in the Noble Eightfold Path is repeated in the Five Precepts, as explained below. Thus continuing to show an interconnectedness that is found in the principles of Buddhism.

\subsection{The Five Precepts}

Some Buddhist Scholars view that the Five Precepts are the true source of ethics in Buddhism. The five precepts and Buddhism can be compared to the 10 Commandments that are found in Christianity. They are a list of vows that are taken on by monks and consist of acts that they should never do.

The Five Precepts

1. Taking a life

2. Stealing

3. Sexual misconduct

4. Lying

5. Taking intoxicants

Out of all the precepts in particular it is the fifth precept (do not take intoxicants) it is the most pertinent to the study for two reasons. The first reason is that the term "intoxicant" must be explored further as it is unclear what is considered to be an intoxicant and what is not under the Buddhist paradigm. While Buddhists make it clear that what ought be considered as an intoxicant is a substance that creates an unclear or unsound mind, the purpose of the fifth 
precept was primarily intended to keep monks from consuming alcohol. There is a story in Buddhist lore of a high ranking Buddhist lama who came across a demon disguised as a beautiful woman who was carrying beer and leading a goat. The woman forced the lama to do one of three acts: kill the goat, sleep with the woman, or drink the beer. The lama, believing that the beer would do the least amount of harm, drank the beer. Afterwards, the lama became intoxicated and proceeded to kill the goat and sleep with the woman (Ortner, 1973). The moral to take away from the story is that intoxication leads to the breaking of the other precepts. This is the same worry that Buddhists have when it comes to the use of other sorts of drugs, i.e. how do they cloud the mind or one's own judgement and do the drugs cause the person who uses them to break other precepts?

Over the centuries the monastic communities have expanded the definition of an intoxicant to include other drugs (Ortner, 1973). The second reason this precept will be examined is because of the fact that Buddhists have this intoxication principle as an immorality and they therefore could have some background knowledge on intoxicants and may be able to understand the nature of these medications. Depending on how PCE affects the mind, it may be considered as an intoxicant under the Buddhist view. For instance, if a person becomes so focused on what she is doing that she ignores the rest of her surroundings entirely, a Buddhist might say that this clouds the mind by making the individual less mindful. This notion will be further explored in chapter 5 during the results of interviews with Buddhist monks and nuns.

The five precepts in combination with the four Noble truths and the Noble Eightfold Path would make up the general Buddhist ethic. This already paints a 
very complicated picture of Buddhist ethics and can make its application to ethical issues rather difficult. The interrelatedness of morality with other aspects of Buddhism makes it difficult to single out in the ethics.

\subsection{Conclusion}

As previously mentioned in this chapter, Damien Keown considers the ethical framework of Buddhism to be a form of teleological virtue ethics (2005). This assumption will be taken and considered as a backdrop when generating a framework from the views of Buddhist monastics. The reason why this particular view will be considered more so than others is because it takes into consideration various aspects that make up the Buddhist ethic. It was also shown in this chapter that the Buddhist ethical framework is primarily made up from the Noble Eightfold Path and the Five Precepts with special attention being paid to the fifth precept of intoxication. A great focus is placed on the Five Precepts as previous Buddhist scholars traditionally have. When exploring the ethical framework further it is important to keep these previous considerations in mind. 


\section{Chapter 5 \\ Results and Discussion of a Qualitative Analysis of Buddhist Monastics' Perspectives on PCE}

"The man whose hands are controlled, whose feet are controlled, whose words are controlled, who is self controlled in all things, who finds the inner joy, whose mind is self-possessed, who is one and has found perfect peace - this man I call a monk." The Dhammapada

\subsection{Introduction}

Eight different Buddhist monks and nuns were interviewed to construct a Buddhist ethical framework and to identify the proper moral use of pharmaceutical cognitive enhancement. This was done in order to identify the relevance and significance Buddhist ethics can add to the current discussion on PCE. The results of the discussions are presented and explored in this chapter. There were two key themes that emerged from the data after analysis, Buddhist Ethics and Ethics of PCE. The themes can be then divided into smaller categories. In Buddhist ethics the key categories mentioned here are "The Noble Eightfold Path", "Meditation", and "The Fifth Precept".

The second theme that will be discussed will be PCE and contains the following categories: "University Students", "Pharmaceutical Companies", and "Analogous of Sport". These categories will be a sort of continuation on the previous discussions of chapters 2 and 3 . These categories were comprised of smaller concepts, which in turn were generated by codes from the data.

\subsection{Buddhist Ethics}

Damien Keown $(1995,1992)$ considered the Buddhist ethical framework to be a form of teleological virtue ethics. It seems that the data can help support 
such a framework. From the data there are two key aspects that hold the most weight in terms of generating a Buddhist ethical framework: The Noble Eightfold Path, Meditation and the Five Precepts.

In the Noble Eightfold Path category concepts such as interconnectedness and "Buddha-like" character are explored. These concepts arose from the discussions of the eightfold path. The "Buddha-like" character concept is a way of understanding how the eightfold path applies to individuals and how it can be applied to certain ethical situations. The concept of interconnectedness explores how the different paths of the Noble Eightfold Path interplay with one another and how the different parts of the path effect the morality found in Buddhism. It is also compared to Aristotle's view of virtue ethics in order to understand it in a western context.

Meditation as a category explores the concepts of Buddhist cognitive enhancement and differences between the means of enhancement (i.e. the difference between meditation and medication). One such example is mindfulness meditation and how it can enhance the mind. Comparisons and contrasts towards medication are also explored. The West also tends to misunderstand certain aspects about meditation and consider it to be only a good alternative to medication. However, some of the participants say that meditation can have negative side effects in much the same way as medication, and this concept is further explored.

The Five Precepts themselves do not make up a category of their own in the theme of Buddhist ethics; rather it is the Fifth precept (do not take intoxicants) that will make up the third category. The Five Precepts will be a concept that is considered within the category of the fifth precept. Since the 
Buddhist ethical framework is more complex than it initially seems, some of the aspects of the Buddhist ethical framework for focused on more heavily in the conversations carried out in the interviews with the monks as they stressed these key areas. These categories were found to be the most important aspects of the Buddhist ethical framework to consider on PCE.

\subsubsection{The Noble Eightfold Path}

In general the Buddhist ethical framework does care greatly about reducing suffering, as seen previously from the Four Noble Truths. But suffering, according to some Buddhists, has been misunderstood in the west. One such example that was cited often by the participants in this study in the interviews is anger. According to participant $A$, "anger is a form of suffering". Dukkha is the frustration that individuals have throughout their life as well as physical suffering (Harvey, 2000). It constitutes the emotional and psychological forms of suffering, such as anger or depression. In order to alleviate and eliminate dukkha one must follow the eightfold path, as the fourth noble truth states. However, to live a moral life in a Buddhist view a person must follow both the Noble Eightfold Path and The Five Precepts. There was some contention between the participants about which of the two where the most important or the crux of the moral framework. But all found that both aspects were integral to the framework. Here will be an analysis of only the Noble Eightfold Path, as the fifth precept as well as the concept of the Five Precepts will be analysed later in the chapter.

A goal for Buddhists is to become more "Buddha-like" in nature. This means that the Buddhists try to shape and change their character to become 
more like that of the Buddha, Siddhartha Gautama. The shaping and development of a person's character seems Aristotelian in nature, and some similarities can be found. There was heavy reliance on virtue when asking the Buddhist monks to describe the eightfold path. The ideal virtues are virtues that are found in the Buddha. But this does not mean that there is a Euthyphro dilemma here ("Is the pious loved by the gods because it is pious, or is it pious because it is loved by the gods?" 10a). Here, Buddhists would accept the former and are happy to do so. As previously stated, Buddha only found the objective moral laws and did not invent them according to Buddhist teaching. So according to Buddhist teaching, the Buddha is the manifestation of natural moral law and something that should aspired toward, like that of Aristotelian Eudaimonia or human flourishing. Hence, Buddhist ethics is meant to be a form of character shaping and development.

A concept that emerged from the interviews was "interconnectedness" and it was often in relation to the discussion of the eightfold path. Interconnectedness is supposed to be found in the eightfold path. As previously mentioned in the literature review, the eightfold path is split into three different sections, wisdom, morality, and meditation. When considering morality there are three parts to its section, right livelihood, right speech and right intention. All of these are supported not only by each other but they are also supported by the other categories (wisdom and meditation) of eightfold path. This support of morality and moral development from other aspects of eightfold path is what is meant the interconnectedness that is found there.

For example, according to one participant, a Buddhist must at least have an understanding of the morality category of the eightfold path. In combination 
with another category such as wisdom there will be what is called "moral manifestation". This is a result from having, as participant $L$ considers, a "good understanding of the nature of things and your experiences and things like that". With the support of the other two categories the character of the individual becomes more virtuous or "Buddha-like". The moral manifestation relies on the phenomenological experiences of individuals and a person's understanding of their own experience. This is said to develop other virtuous qualities such as empathy. If a person understands their own experience they are more likely to understand the experiences of others, hence the heavy emphasis on interconnectedness.

The eightfold path is not necessarily as strict set of standards or paths that one must adhere to. It is more individualistic and each distinct person has his or her own "middle path". This means each person must have the right balance between all the paths that is relative to themselves. As one monk explains:

"So I am not about going for a fixed black and white because the way we look for a Middle Path, not the Middle Path but a middle path that each individual will have to build their own Middle Path, the guide is there... For some people number eight may be prominent. For some people number one, the eight factors may be more prominent. These things we understand as the nature of individuality. This is okay." - D

It is only through the combination of all of the eight different paths that the elimination of dukkha can occur. In the next category, meditation is explored and shown how integral it is to Buddhist ethics, as one monk explains below. 
"To take ethics separately from everything else in life, it would be hostile to Buddhist teaching or to the Buddhist philosophers. To take meditation away from ethics would be the same." - D

\subsubsection{Meditation}

Meditation is an important aspect of the Buddhist ethical framework. An entire third of The Noble Eightfold Path (what some monastics and scholars consider to be the centrepiece of Buddhist ethics) is dedicated to meditation. As previously mentioned this interlocking of the different categories found in the eightfold path is a key feature for the framework. Without meditation or mindfulness, the ethical framework is not as strong. There is also the fact that meditation can be considered as a form of cognitive enhancement as it tries to increase a person's "cognitive capabilities". Thus, meditation is something that deserves to be explored here and its characteristics ought to be compared with PCE.

"Meditation is about taming the mind. You learn to tame the mind. You learn to observe and see your own habits, recognize which habits are beneficial, which habits are harmful." - Z

This monastic mentioned that a reason to meditate was to tame a one's own mind. But this taming of one's own mind is, again, more about changing a person's character rather than simply increasing their mental capabilities. What is typically meant by cognitive enhancement for most monks and nuns is to let go of certain emotions or habits that cause a person to suffer. This is a different 
conception of enhancement than what is typically found in the West where it is meant to increase the mental faculties that are already present in an individual. As previously mentioned in Chapter 3 under the sections of Definitions of Enhancement and The Three Paradigms there are different definitions of enhancement as well as different paradigms towards cognitive enhancement. It seems clear from the discussions with the Buddhist monks that they do not fall into the common categories of enhancement within the bioethics community. While individuals such as John Harris (2010) or Henry Greely (2008) would subscribe to the capabilities definition of enhancement along with the cognitive enhancement paradigm, Buddhists would more than likely agree with Savulescu (2006) in adopting a wellbeing or welfare definition of enhancement. In addition, the Buddhists I have interviewed seemed to lean more towards the drug abuse paradigm by concerning themselves more with the safety and efficacy of the pharmaceuticals.

To digress back into the category of meditation, according to the monastics interviewed there is a lot to be said for the benefits of meditation. Most of which have to do with the calming of the mind and finding inner peace. However, some of the monks noted that with the right concentration and training other attributes of cognition can be enhanced such as focus and perception. Most who practice meditation usually report to have a better mood, feel more happy and energetic, and less angry or depressed. Many of the monastics have been practicing meditation for decades. So it comes as no surprise that they would see many positive benefits toward the use of the practice. 
"Meditation, if it is undertaken under a skilful teacher then I think it can be very beneficial for people, for their mental health. Meditation in the Buddhist tradition is more than cognitive ability. It talks about cognitive capacity as well as the way we look at the world." -D

The monastics were asked at a point during the interview to compare and contrast meditation with medication. If the monks did prefer meditation to medication (or vice versa) then there needed to be clear and distinct reasons for choosing one means of cognitive enhancement over the other. Comparing and contrasting also allows for clarification of ideas, as they the monks may not view meditation and medication as two similar means to achieve cognitive enhancement.

In terms of contrast, there is an "internalizing" quality that is found in meditation that cannot be found in pharmaceuticals. The aim of meditation to help cultivate certain aspects whether it is cognitive, spiritual, or otherwise. This cultivation or development of an individual is not found in pharmaceuticals, as the effects are neither permanent nor long lasting. This leads back to the invasiveness of the pharmaceuticals and the amount of work that is required in order to cognitively enhance.

"Meditation, you can internalize the meditative qualities. With meditation you are trying to do mindfulness, you are trying to focus on concentration, but you are now staying just with concentration and feel good at that. You know, you are using this concentration to examine your emotion, to investigate your emotion, if necessary to purify it. Once, you 
know, you are doing that, you will find out that certain qualities become internalized second nature." - D

There is also the difference of moral and spiritual development. In contrast to pharmaceuticals, meditation helps to develop a moral character as previously seen from the creation of the Noble Eightfold Path. When looking at spiritual development the goal of meditation is to become an enlightened being, just as much as the Buddha. There is no pharmaceutical that will allow any Buddhist to this. Because of the attached moral and spiritual benefits that come with meditation that cannot come from pharmaceuticals, it is no surprise that the Buddhists would prefer to use meditation.

One of the other differences often found in discussions with the monastics is the fact that meditation does not rely on an "external" stimulus. In meditation there is no foreign substance that is being placed into the body. Whereas in the case of PCE, there is a full reliance on the pharmaceutical in order to enhance the mind. This in particular is a negative in Buddhist ethics as the ultimate goal for Buddhism is to become self-reliant:

"But I think the main difference would be that these drugs have other side effects. In Buddhist meditation you are not consuming anything." $-P$

There are some similarities that can be found between the meditation and medication as well. In terms of concentration, most monastics found similarities in the effects that are produced by the two ways of enhancement. Meditation has 
been shown to help improve concentration and focus. To the monastics, even the intensity of the focus can be achieved through both means of enhancement.

A couple of the monastics were rather insistent on a particular point about meditation. To the practitioners, there is a misconception in the portrayal of meditation. It is possible for meditation to be an "unpleasant" or "uncomfortable" option for certain individuals and can have negative consequences. Meditation is not a practice that will always calm the mind or help someone find peace.

One Buddhist scholar explains the importance of understanding the uncomfortable side of meditation:

"That's not necessarily the case, especially if you kind of use mindfulness tools such as breathing in and out or whatever. When your mind actually has a chance to come down you might then identify other kind of thoughts, negative thoughts or positive thoughts or emotions as it were. Those can be very disturbing for people." - K

The monastics emphasise the fact that this is a rare occurrence. But it does happen. The help eliminate the risk of becoming disturbed from meditation, the monastics recommend finding a "skilful teacher", one who knows and understands the difference forms of meditation, has a good reputation for teaching meditation, and has practiced the art for a long time. While the risk for disturbances and unpleasant experiences are always there in meditation, the monks believe it is still a safer alternative to using pharmaceuticals (aside form individuals who require pharmaceuticals for therapeutic purposes). Not only do 
the benefits of meditation help to increase cognitive capacities, it also helps to shape moral character, in line with Aristotelian ethics this is meditations ultimate purpose; to shape the moral character of an individual so that they may reach a state of human flourishing while at the same time trying to reduce the dukkha found in the person.

There is without a doubt that Buddhists view the integration of meditation and ethics is an essential aspect of the Buddhist ethical framework.

"When Buddhist meditation focuses on emotion, you focus on the emotion not just for psychological benefit. I will focus on the impact of emotion on ethics. How people can become ethical or unethical and how that can be kind of not in the emotions. This is partly what we do when we focus on the mind-set." - $P$

\subsubsection{The Fifth Precept}

An important focus in this project is on the fifth precept of The Five Precepts, "Do not take intoxicants". It is important to understand whether or not using PCE fails under the fifth precept as an intoxicant. If it does, then under the Buddhist view the use of PCE is morally impermissible. Even if it is found that PCE does not violate the fifth precept, there is still a long way to go and a lot to consider before accepting the permissibility of PCE. So what does intoxication mean exactly? According to one monk:

"[intoxication] is not a black and white situation with that precept. That precept, the purpose of the fifth precept is about people losing their 
awareness, their mindfulness and that absentmindedness leads them to behave in a way that is not considerate to themselves and to other people, i.e. to be in violation of the other precepts." - D

Here it can be seen that the extent to which PCE breaks the fifth precept depends on whether or not an individual is aware or mindful and does not lead to immoral behaviour. At first glance it may seem that PCE does not break the precept, as it does not necessarily cause intoxicating effects. In addition, the pharmaceuticals are meant and designed to enhance cognition and awareness. But it might be the case that with individuals who would use ADHD medication to their advantage may be breaking the fifth precept in the form of side effects. Individuals who use PCEs will sometimes find themselves with "hangover like symptoms" the morning after taking the PCE. These symptoms could cause a lack in mindfulness or awareness. One Buddhist scholar thought that the fifth precept was being broken indirectly.

"Then if the drug itself and the side effects has put you in a very deluded state, which it sounds like they are doing that, when you come off the drugs your mind is sluggish and things like this. So in a way you are kind of in a deluded state, much more deluded than regular... So in that sense they are kind of breaking the rules." - K

The focus here is on the after effects of using PCE's and what can happen to one's cognitive function. It may seem to the Buddhist that because of these after effects that the drugs would do more harm than good. 
"I can't quite imagine taking a drug and doing the work and afterwards if you are left with a very bad effect then what is the worth of doing that?" - L

Of course, all of the current developments of the pharmaceuticals try to mitigate and reduce the after effects. The drugs themselves are designed for individuals who require cognitive therapy, an already vulnerable population. The ultimate goal, in terms of cognitive enhancement, is to have a pharmaceutical that can increase cognitive functioning with no side effects whatsoever. Which is not necessarily what current pharmaceutical developers are trying to achieve. But there are still some side effects of using the medication to enhance the mind.

"Although you had a clear mind initially, after your mind is really a blur, which is one of the kind of main hindrances of Buddhist path and Buddhist enlightenment, as you know." - P

Even if the ideal pharmaceutical is reached and the side effects are minimal at worst. It may be that a stricter adherence to a broader version of mindfulness and awareness is necessary under the Buddhist view. If a student is using methylphenidate to enhance their cognition and focuses on a particular subject or matter at hand, it may also be the case that the student is solely focused on their work and pays little to no mind towards his or her surroundings. If this is true, then this would fall under a state of mind that could be considered intoxicated to Buddhists. Thus the use of the pharmaceutical is 
immoral. This is all relative to how a person normally behaves and how mindful an individual normally is to begin with. It leads back into the individual Eightfold Path as previously mentioned. It is also further evidence to support a case-bycase analysis of PCE, because of the fact that the ethical view and standard is on an individual level.

\subsection{Ethics of PCE}

The second theme involves the use of PCEs. The monastics were asked if the use of PCE was morally permissible. One in which the monastics took a great interest was the utilization of PCE in university students for the purposes of academic achievement. University students will typically use ADHD medication, methylphenidate, as means to increase their energy, working memory, and focus in order to produce a large amount of their coursework.

University student use of PCE has been a common motif throughout this project and is the subject of a category in the theme of Ethics of PCE. This category in particular arose from questions that were asked from the topic guide and the conversations continuously led back to this example. In the section below the moral permissibility of student use of PCE is explored. In general the monks were unsure of moral permissibility of cognitive enhancement in universities and requested more information and context in order to reach a conclusion.

The category of Pharmaceutical Companies explores concepts of intention and society influence. Some of the Buddhists worry over the growing influence that the big pharmaceutical companies have in the West. They are also worried over their intention of creating pharmaceuticals for the purposes of cognitive 
enhancement. The worry most stems from pharmaceutical companies being businesses and the nature of business is to make profits. These ideas will be further explored below.

In the Analogous of Sport category there are two key concepts that emerged from the data namely competition and cheating. These emerged as a way for the monastics to understand PCE in the academic setting by drawing parallels to a previous bioethical issue that they understood. It should also be noted that the category of comparing PCE to sport emerged organically, meaning that the monks and nuns brought these comparisons up themselves and not from the researcher.

\subsubsection{University Students}

In general, there is uncertainty found in the monastic community on the permissibility of PCE, no mater what the scenario. This includes uncertainty for the situation in which university students use PCEs to in order to perform better in their academic coursework. When asked about this scenario many monastics seemed confused by the situation. They typically asked more questions and seemed genuinely inquisitive about the context of the situation.

For the university students' situation, they were very curious as to why the students feel they need to cognitively enhance in this manner, or why they feel the need to risk the side effects in order to produce their coursework. To most Buddhists, there needs to be consideration for all parties involved. They also wanted to know more about universities perspectives and whether or not the pharmaceuticals and their use are doing any harm to the institutions. Here again, a great importance on the welfare of the student is placed as the most 
important concept to consider. Which leads to the conclusion that the Buddhists interviewed are still considering the issue under the drug abuse paradigm as previously explained in section 3.6.1.

It seemed to the monks that while they have their reservations on students using these PCEs most found nothing inherently wrong with the technology or pharmaceuticals in of themselves. They even placed a great amount of freedom upon the neuro-typical individual that would use PCE stating, "It's their choice". This is unsurprising since the analysis of the Buddhist ethical framework revealed an importance on individually in The Noble Eightfold Path.

\subsubsection{Pharmaceutical Companies}

There were concerns raised about pharmaceutical companies when discussing considerations about PCE. The Buddhists themselves, without prompt from the researcher, raised these concerns. Most of the concerns were based on the intention the pharmaceutical companies have when producing the sort of pharmaceuticals that increase cognitive capacities. While all PCE is currently developed for therapeutic purposes, it would seem that the monks and nuns still have their reservations. Mostly that the pharmaceutical companies are going about the issue from "the wrong angle".

The two key aspects of pharmaceutical companies that the monastics considered were intention and influence. Supposing that the intention of using pharmaceuticals was for enhancement purposes, it might lead to the continued growing power and influence of pharmaceutical companies. One nun even said, "There is "something unethical... about the way these are becoming too powerful, the pharmaceutical companies." - Z. The fear with using pharmaceuticals to 
cognitively enhance is that it gives more pharmaceutical companies power and influence within our society. It is an industry that is already filled with ethical issues. "That is where the ethics I think are going wrong, in the big businesses." $Z$.

However, this should not mean that the Buddhists completely distrust pharmaceutical companies. They believe that the pharmaceutical industry has value for society and believe that it can help people. It is only when the companies grow too large or when their sole intention is to make a large profit is there "distrust" among the Buddhist monastics.

\subsubsection{Analogous of Sport - Competition and Cheating}

PCE has been argued to be analogous to another bioethical issue, performance enhancement in sport. The most common comparison is that PCE is akin to steroids in sports. In the interviews conducted, this analogy was explored further. Two key aspects are further explored here with the comparison of PCE and sporting enhancement, competition and cheating.

First, healthy competition has been a reason to consider a favourable permissibility towards the use of steroids in sport. The same consideration has been put forward towards a more liberal use of PCE. But for the monastics, the use of PCE in academia or steroids in sport does not promote healthy competition. This notion of using PCE to boost academic performance even seemed a little foreign to the monastics.

While they understand why lay people participate in competition with one another, there is still evidence to support that Buddhists would rather see less competition as a whole. "If people are driven to achieve something in the 
competitive world, I can understand people will go for things like that.", as participant $L$ mentioned. This is in line with previous ideas found in Buddhism, mainly the taking of refuge from society and its troubles. For Buddhists, healthy competition is minimal competition. This is because competition leads to further suffering, mostly towards one's own ego. The idea is that competition leads individuals to suffering because the individuals who participate in competition are trying to achieve something that, Buddhists believe, has little to no value.

"It's all this ego-based idea that we identify with 'You have to be the best'”..."If you are not the best, if you are not number one, if you are not recognized... you are a nobody" - L

To harm another person's or one's own ego through competition is not something that is considered to be proper character development under the Buddhist lens. It is safe to conclude that the argument by healthy competition will not be considered as a sound argument under Buddhist ethics and should not be considered as a positive aspect for the use of PCE. If the notion of competition were to be eliminated from the picture and individuals only use PCE for recreational purposes, then the Buddhists would probably have less of an issue to take up on the subject.

Another reason that the Buddhists thought PCE use was not healthy competition was because of the fact that an individual would be relying on the drug rather than the person's current intelligence. "Well, I don't think its healthy competition. That's for sure because healthy competition would be just relying on your intelligence." This leads back to the previous chapter in which the 
permissibility of PCE is linked to the abilities found within the pharmaceuticals themselves.

Some conversations continued to explore the analogy between steroids in sport and PCE. This time it was on the subject of cheating. The question was raised to the monastics as to whether or not they found that the students or athletes were cheating. There was a slightly less of a consensus found among the monastics on this issue.

One monk was very insistent about his feelings towards the athletes who used performance-enhancing materials.

"Seven years [Lance Armstrong] cheated all of his rivals, his companions in his field. He cheated them all. So why? He wanted to feel special. You know? 'Look at me, I won seven' or whatever his reason may be. But either way he robbed somebody of an equal chance." - L.

Another was sure of the fact that the athletes were cheating, yet unsure if the students were cheating at all. "I think for the sports people they would say that is cheating, but for academic study, for study for education, I don't really know what to say for cheating." His particular reason for this was because he considered the use of PCE as something that would not help with skill development. Thus, while someone may use PCE to get through their education it does not necessarily mean that they will succeed in securing a job position afterwards. In a sense, the students are not really cheating the university but rather themselves. "People still interview you and you still have to perform in other tests." This leads back once again to the understanding of what it is exactly 
the pharmaceuticals are capable of doing. For most Buddhists, their understanding of what the pharmaceuticals can do is based on the notion that they do not improve the uptake and retention of information. Rather they simply increase such aspects as alertness or concentration.

Yet it still seems that competition and cheating are not the top concerns for the monks. The monks were still more concerned with the long-term side effects from the pharmaceuticals. They are also more concerned with how the pharmaceuticals will affect other individuals, how it will shape their character. One monk believed that students are, more or less, cheating themselves than they are the universities. This makes it seem more likely that the Buddhist monks view PCE under the drug abuse paradigm and that they view the use of PCE as more of a public health issue. They never really considered the use of smart drugs as lifestyle drugs or as cognitively enhancing pharmaceuticals.

As participant $D$ put it, "I am more concerned with the drug takers damaging themselves and becoming a bad example. I don't really worry about their achievements because we can assess a person's ability in many other ways."

The most pressing concern with Buddhist monks and scholars has been the safety the individuals who decide to use PCE. After safety has been confirmed it then seems that how the use of PCE shapes a person's character is the next consideration. Competition is not as much of a concern for the monks and scholars interviewed, it maybe in part because they see little importance to competition to begin with.

On the whole, it seems that the amount of experience the monastics have with this particular issue is minimal to none at all. Many were not aware that the issue of PCE ever existed. This must be noted as some of the Buddhists felt that 
their lack of knowledge on PCE would make their advice inadequate. However, the data seems to show that Buddhist monks have reservations about using these pharmaceuticals and are more likely to suggest other means of cognitive enhancement before using PCE's. This could be the result of a bias as the Buddhist monks have a high preference towards their own means of cognitive enhancement. On the whole, the monastics have decided that PCE may not be the best way of enhancing the mind for an otherwise healthy individual. PCE has both positive and negative consequences; it can also shape our character for better or worse. The monastics urge everyone to practice mindfulness and consider moderation when it comes to the use of these pharmaceuticals.

\subsection{Conclusion}

This chapter has covered the results found from the interviews of the participating monks and nuns and has brought about a discussion from the results. Here, two themes have emerged after an analysis of the data using a modified version of grounded theory: The Buddhist ethical framework and the moral permissibility of PCE. This will hopefully bring about a more global perspective on the bioethical issue and make others aware of different ethical frameworks that are not necessarily found in the West.

After analysis, it seems that Damien Keown is certainly correct on the heavily reliance of virtues that are found in Buddhist ethics. There is a heavy reliance on the Noble Eightfold Path, however according to the participants each person has their own balance between the different "paths" or virtues. This ultimately leads to the end of suffering or nirvana. But there is still a large reliance on the five precepts when considering morality in Buddhist ethics. This 
is especially true when it comes to foreign substances that may alter one's state of mind. In this case the fifth precept was the most important to consider for the monks. They worry that the pharmaceuticals could "cloud the mind" or make individuals less mindful of their surroundings while they are too focused on their task at hand. This could possibly lead to breaking other precepts, values, or virtues that would otherwise shape the character of the individual into a moral person. The participants for several reasons favoured meditation. One was the lack of reliance towards an external stimulus. Buddhists place a tremendous value on self-reliance and the expulsion of external stimuli would be favoured since meditation can simply replace PCE in their view. For the Buddhists meditation is not only a cognitive enhancer but a moral enhancer as well and a person does not necessarily receive both with a pill. They also view meditation as less harmful, although there are possible drawbacks to its practice, as stated previously.

The participants were unsure of the moral permissibility of PCE in the context of university students who use the pharmaceuticals to perform better academically. Some saw that there was nothing necessarily wrong with PCE in of itself provided the intention is correct and the harm to oneself or others is minimal. Many considered it to be cheating for university students and thought that students ought to seek other, less hazardous, forms of cognitive enhancement. In part they tend to associate with the public health paradigm when it came to PCE rather than the attitudes and paradigms of thought that are typically found within the Western public and bioethics communities. Safety, health, and harm (be it physical or mental) were the primary concerns for Buddhists rather than issues of fairness or egalitarianism. They also greatly 
compared the use of PCE to doping in sport. They seemed to find many similarities between the two contexts and found that many of the issues that are taken up over doping in sport are the same concerns that they have this issue.

For the monastics, students using PCE for academic performance is a symptom of larger problems found within society. Parts of the problem stem from the how we view competition, while other parts are from the interests and intentions of the pharmaceuticals companies and business. These concerns need to be addressed further in order for the discussion of PCE to gain any ground. Certainly more research ought to be conducted in order to continue the discussion of PCE through the lens of Buddhist ethics. 


\section{Chapter 6 \\ Conclusions and Implications for Bioethics}

"The traveller has reached the end of the journey! In the freedom of the Infinite he is free from all sorrows, the fetters that bound him are thrown away, and the burning fever of life is no more." - The Dhammapada

The purpose of this project has been to explore the relevance of Buddhist ethics within the context of PCE as well as to determine what possible moral conclusions that can be derived from Buddhist ethics in order to frame the discussion of PCE use in bioethics in a more global context. Overall, the project revealed some unique insights from the Buddhists and furthered the conversation. While the project does confirm Damien Keown's ethical framework it showed that the application of Buddhist ethics to the bioethical issue of PCE is possible.

\subsection{The moral conclusion}

Insofar there is no overarching moral conclusion on the permissible of PCE under the Buddhist ethical lens. The Buddhists did not necessarily believe that the use of PCE is totally and morally wrong in all cases. Certainly they believe that the use of PCE ought to be used in cases of therapy, as do most in the West who ponder the issue. But in terms of utilizing PCE for non-medical purposes, they are more ambivalent. Buddhists do hold the values of autonomy and personal freedom in high regard and the majority of the Buddhists interviewed believed that, if used in moderation then it there is nothing inherently wrong with the use. Of course, the meaning of the term "moderation" is open to interpretation here. The ethical framework is designed to take context into account, and so when we look at the use of PCE from different contexts (such 
as in the context of pharmaceutical companies or university students) we may end up with different moral outcomes.

\subsection{Summary of Relevance}

In order to create a more global ethical debate and not fall into the trap of ethical imperialism it is important to view the bioethical issues of the day through different cultural lenses. Buddhist ethics provides a unique framework that is not often found in the West. Similar aspects of the framework can be cross culturally compared such as the teleological and virtue aspects. However, while these aspects of the framework can be compared to western notions of consequentialism and virtue ethics, the metaphysical foundations for them are different. As previously mentioned, Buddhists do not necessarily believe in a lasting personal self, even though most believe that the essence of the being will be reincarnated and affected by karma.

But what Buddhist ethics also brings to the conversation is the understanding of the interconnectedness of all things. How pharmaceutical companies go about their business could effect how university students obtain or use PCE. It also points out that much of the problems in PCE policies lie with western notions of competition. For the Buddhist, the ultimate goal towards competition is to eliminate it as competition itself leads to more suffering. The Buddhist would try to convince university students to learn and enhance their mind in a way that is not for the sake of winning out over their peers but for the sake of bettering themselves and furthering their knowledge. How a person views competition (academic or otherwise) will effect that person's decision to enhance. 
This dissertation has also opened the discussion of PCE from the view of Buddhist ethics. Little to no extensive research has been done on PCE from the view of the Buddhist. Primary research was necessary in order to fully grasp the view Buddhists have on PCE and cognitive enhancement as a whole. This project will serve as a stepping-stone towards future research and a more in-depth discussion of PCE and Buddhist ethics. 


\title{
Appendix A: Research Ethics Committee Approval Letter
}

\author{
Research Ethics Office \\ King's College London \\ Rm 5.12 FWB (Waterloo Bridge Wing) \\ Stamford Street \\ London \\ SE1 9NH
}

24 March 2015

TO: Andrew Barnhart

SUBJECT: Confirmation of Approval

Dear Andrew,

Thank you for submitting your Research Ethics Minimal Risk Checklist. This letter acknowledges the receipt of your checklist; your Research Ethics Number is MR/14/15-51. Be sure to keep a record of this number and include it in any materials associated with this research.

\section{Record Keeping:}

In addition, you are expected to keep records of your process of informed consent and the dates and relevant details of research covered by this application. For example, depending on the type of research that you are doing, you might keep:

- A record of the relevant details for public talks that you attend, the websites that visit, the interviews that you conduct

- The 'script' that you use to inform possible participants about what your research involves. This may include written information sheets, or the generic information you include in the emails you write to possible participants, or what you say to people when you approach them on the street for a survey, or the introductory material stated at the top of your on-line survey.

- Where appropriate, records of consent, e.g. copies of signed consent forms or emails where participants agree to be interviewed.

Audit:

You may be selected for an audit, to see how researchers are implementing this process. If audited, you will be expected to explain how your research abides by the general principles of ethical research. In particular, you will be expected to provide a general summary of your review of the possible risks involved in your research, as well as to provide basic research records (as above in Record Keeping) and to describe the process by which participants agreed to participate in your research.

Remember that if you have any questions about the ethical conduct of your research at any point, you should contact your supervisor, the Research Ethics office, or a member of your Department's

Research Ethics Panel for advice.

\section{Feedback:}

As KCL is currently trialling the Minimal Risk Process, you may be selected to provide feedback on the Minimal Risk guidance, form and process. You can also provide feedback on the process by emailing rec@kcl.ac.uk.

We wish you every success with this work.

With best wishes

Research Ethics Office 
Appendix B: Information Sheet

REC Reference Number: MR/14/15-51

\section{YOU WILL BE GIVEN A COPY OF THIS INFORMATION SHEET}

\section{"Meditations on Drugs": A Buddhist Ethical Approach to Pharmaceutical Cognitive Enhancement}

You have been invited to participate in a research study on Buddhist ethics and pharmaceutical cognitive enhancement. Since Buddhism uses meditative techniques to enhance the mind, we are curious as to what Buddhists believe to be morally permissible when it comes to the use of smart drugs in order to enhance our cognitive capacities. Your input will be of great benefit to the ethical debate over the use of smart drugs.

\section{What is the purpose of the study?}

The purpose of this study is to generate a Buddhist ethical framework and apply the framework to the bioethical issue of the use of pharmaceutical cognitive enhancers or "smart drugs".

\section{Why have I been invited to take part?}

You are a Buddhist monk, scholar, or expert on meditation and understand how Buddhists practice ethics and what ethical values are important in Buddhism.

\section{Do I have to take part?}

You do not have to take part in this research. If at anytime throughout the conducting of research or interview you wish to no longer participate, you are free to leave. You do not need to give any reason for your cessation of participation.

\section{What will happen to me if I take part?}

A one-hour interview will be conducted in a private setting of your choosing. You will be asked questions pertaining to Buddhism, ethics, meditation, and pharmaceutical cognitive enhancement or "smart drugs". You are free to say anything wish on these topics.

\section{What are the possible risks of taking part?}

There is minimal risk in taking part in this study. If you feel uncomfortable about any topic that is being discussed, please let us know and we will either change the subject or stop the interview. If you feel as though you do not want the interview to be used in this research you have two (2) weeks to inform us about your wishes.

\section{Will my taking part be kept confidential?}

Your name will be kept as a part of the data gathered in a secure hard drive. You have the option to remain partially anonymous. This means that your name will be changed in the study and you will not be identified in the publication. Your name will still be kept on a secure file for coding purposes but it will not be released. If you wish to remain partly anonymous you may indicate so on the consent form.

\section{How is the project being funded?}

This is a self-funded project by the researcher for the purposes of a dissertation at King's College London.

\section{What will happen to the results of the study?}


The results of the study will be used for a masters dissertation and published through King's College London.

\section{Who should I contact for further information?}

If you have any questions or require more information about this study, please contact me using the following contact details:

Email: andrew.barnhart@kcl.ac.uk

Tel: +44 (0)7507356966

\section{What if I have further questions, or if something goes wrong?}

If this study has harmed you in any way or if you wish to make a complaint about the conduct of the study you can contact King's College London using the details below for further advice and information:

\section{Silvia Camporesi}

Lecturer in Bioethics \& Society

Director, Bioethics \& Society Postgraduate Programme

Department of Social Science, Health \& Medicine

King's College London

D6, 2nd floor, East Wing

WC2R 2LS London

Email: silvia.1.camporesi@kcl.ac.uk

Tel: +44 (0)2078487918

Dr. Kate Crosby

King's College London

Room 3.03, Virginia Woolf Building,

22 Kingsway

London, WC2B 6LE

Email: henrietta.crosby@kcl.ac.uk

Tel: +44 (0)2078481453

Or email: rec@kcl.ac.uk

Thank you for reading this information sheet and for considering taking part in this research. 


\title{
Appendix C: Sample Consent Form
}

\author{
Version Number 1-09/04/15
}

CONSENT FORM FOR PARTICIPANTS IN RESEARCH STUDIES

Please complete this form after you have read the Information Sheet and/or listened to an explanation about the research.

Title of Study: _"Meditations on Drugs": A Buddhist Ethical Approach to Pharmaceutical Cognitive Enhancement

| King's College Research Ethics Committee Ref:_MR/14/15-51

Thank you for considering taking part in this research. The person organising the research must explain the project to you before you agree to take part. If you have any questions arising from the Information Sheet or explanation already given to you, please ask the researcher before you decide whether to join in. You will be given a copy of this Consent Form to keep and refer to at any time.

I confirm that I understand that by ticking/initialling each box I am consenting to this element of the study. I understand that it will be assumed that unticked/initialled boxes mean that I DO NOT consent to that part of the study. I understand that by not giving consent for any one element I may be deemed ineligible for the study.

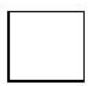

Please ticl or initial

1. I confirm that I have read and understood the information sheet dated [INSERT DATE AND VERSION NUMBER] for the above study. I have had the opportunity to consider the information and asked questions which have been answered satisfactorily.

2. *I understand that my participation is voluntary and that I am free to withdraw at any time without giving any reason. Furthermore, I understand that I will be able to withdraw my data up to two weeks after the interview.

3. I consent to the processing of my personal information for the purposes explained to me. I understand that such information will be handled in accordance with the terms of the UK Data Protection Act 1998.

4. I understand that my information may be subject to review by responsible individuals from the College for monitoring and audit purposes.

5. Anonymity is optional for this research. Please select from the following 3 options:

a. I agree to be fully identified
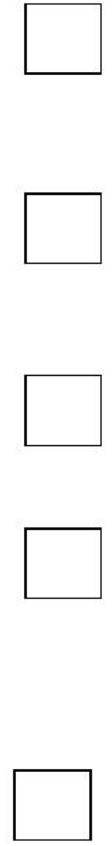
b. I agree to be partially identified

c. I wish to remain anonymous

6. I agree to be contacted in the future by King's College London researchers who would like to invite me to participate in follow up studies to this project, or in future studies of a similar nature.

7. I agree that the research team may use my data for future research and understand that any such use of identifiable data would be reviewed and approved by a research ethics committee. (In such cases, as with this project, data would/would not be identifiable in any report).

8. I consent to my interview being audio recorded.

9. I understand that I must not take part if I fall under the exclusion criteria as detailed in the information sheet and explained to me by the researcher. 


\section{Appendix D: Topic Guide}

How long have you been practicing Buddhism?

How often do you meditate?

Have you ever heard of pharmaceutical cognitive enhancement? How would you define it? (if not, explain to them what PCE is)

What do you see as the mental benefits that come from meditation?

Do you think that enhancing our minds can be done with pharmaceutical cognitive enhancement?

To what extent do you think drugs that enhance our mind should be used?

Have you ever heard of "smart drugs"?

\section{Buddhist Ethics}

What can you tell me about Buddhist ethics?

To what extend does Buddhist ethics rely on scripture/experience?

Are means or ends taken into account?

Does a person's character come into Buddhist ethics at all? If so, for what reason?

\section{Methylphenidate for College Students}

*Explain the use of methylphenidate (Ritalin) by college students to participant

Does this seem right or wrong in any way? Why?

Do you consider this drug abuse?

Do you think the students are cheating?

Does this go against any of the Buddhist precepts?

Would you allow the students to take the drug under certain conditions?

\section{Drugs to Enhance Work Efficiency}

*Explain the use of smart drugs in the work place/military

Do you think the permissibility changed in this context? Why/why not?

Do you think this is a part of healthy competition?

Is there any kind of benefit through meditation that you think cannot be replicated in smart drugs? 


\section{Appendix E: Sample Transcript (D)}

D:

The main Buddhist framework is to reduce suffering. Buddhism uses the word 'suffering' very much. There are many misunderstandings about the Buddhist focus on suffering. Some people think the Buddhists are very pessimistic for looking at things, but for Buddhists, for somebody who understands the Buddhist teaching, to see things as suffering actually shows ambition rather than pessimism. So I look at anger as suffering. As you know Buddhist doesn't stop at suffering. Buddhism talks about suffering and how to overcome suffering. So we are serious about overcoming anger, but in order to do this we have to first look at anger as suffering. When we look at anger as suffering the way we do that is we develop a view to stand back and anger becomes impersonal. When its anger in myself the context and the circumstances may be personal, but anger itself, anger as an element of psychology, as a reaction is not unique to me. It is common to people who practice other religions, who practice no religions, rich and poor, man and woman, young and old. So in that sense suffering is... well anger is merely a psychological factor that can cause suffering. It is not unique to anyone. When you see this, when you accept this, when you get angry you don't need to be defensive. When somebody gets angry with you, instead of looking at that person as someone taking on you, you look at that person as somebody who is suffering. Then you have the chance to feel compassion towards that person. This is to look at anger as suffering and to transform this into compassion. This one is about changing our attitude and outlook. In order to do this it is important that we explore our emotion, how emotion shapes our mind, shapes our decisions, dominates our decision, colours the way we look at our day, our weeks, our months. So this is how we look at it. You may say that to look at anger as impersonal phenomenon, I'm referring to this other teaching, nonsense teaching or emptiness in Buddhist, a few may argue this is just a Buddhist concept. But the Buddhist concept is not aimed at monopolizing things for Buddhists. It's about experiencing anger as a universal phenomenon.

Researcher: $\quad$ Okay, alright. So I am also curious... this seems very focused on personal experience. How much does the scripture... how much does scripture and experience play a role in creating this framework?

D:

Buddhist monks and teachers read Buddhist scriptures, but not Muslims. Muslims just practice under certain teachers. They don't examine the experience in their scriptures. They develop certain tools such as non-judgemental mindfulness which is 


\section{Bibliography}

Anonymous, The Dhammapada, (Juan Mascaro, Trans.), Penguin Classics, 1973, London, England.

Angell, M., 1988, "Ethical Imperialism?", The New England Journal of Medicine, vol. 319, no. 16, pp. 1081-1083.

Burnard, P., 1991, "A method of analysing interview transcripts in qualitative research", Nurse Education Today, vol. 11, pp. 461-466.

Cakic, V., 2009, "Smart drugs for cognitive enhancement: ethical and pragmatic considerations in the era of cosmetic neurology", Journal of Medical Ethics, vol. 35, pp. 611-615.

Camporesi, S., 2014, From Bench to Bedside, to Track \& Field: The Context of Enhancement and its Ethical Relevance, University of California Medical Humanities Press, San Francisco.

Cisneros, A.H. \& and Premawardhana, S., 2011, "Globethics.net Principles on Sharing Values across Cultures and Religions" in Sharing Values: A Hermeneutics for Global Ethics, Globalethics.net, pp. 29 - 40.

Coucouvanis, J., 2005, Super skills: a social skills group program for children with Asperger syndrome, high-functioning autism and related challenges, Asperger Publishing Company, Shawnee Mission, KS.

Driver, Julia, "The History of Utilitarianism", The Stanford Encyclopedia of Philosophy (Winter 2014 Edition), Edward N. Zalta (ed.), URL = $<$ http://plato.stanford.edu/archives/win2014/entries/utilitarianismhistory/>.

Fenton, A., 2009, "Buddhism and Neuroethics: The Ethics of Pharmaceutical Cognitive Enhancement", Developing World Bioethics, vol. 9, no. 2, pp. 47 56.

Greely, H., Sahakian, B., Harris, J., Kessler, R.C., Gazzaniga, M., Campbell, P. \& \& Farah, M.J., 2008, "Towards responsible use of cognitive enhancing drugs by the healthy", Nature, no. 456, pp. 702-705.

Glaser, B.G., Strauss, A.L., 1967, The discovery of grounded theory, Aldine, New York.

Harris, J., 2007, Enhancing Evolution: The Ethical Case for Making Better People, Princeton University Press, Princeton, New Jersey.

Harvey, P., 2000, An Introduction to Buddhist Ethics, Cambridge University Press, Cambridge. 
Hughes, J., 2013, "Using Neurotechnologies to Develop Virtues: A Buddhist Approach to Cognitive Enhancement", Accountability in Research: Policies and Quality Assurance, vol. 20, no. 1, pp. 27-41.

Hughes, J., 2007, "Buddhist Bioethics" in Principles of Health Care Ethics, eds. R.E. Ashcroft, A. Dawson, H. Draper \& J. McMillan, 2nd edn, John wiley, Chincester, pp. 127 - 133.

Keown, D., 2005, Buddhist Ethics: A very short introduction, Oxford University Press, New York, NY.

Keown, D., 2004, Oxford Dictionary of Buddhism, Oxford University Press, New York, NY.

Keown, D., 1995, Buddhism \& Bioethics, Macmillan Press LTD, London.

Keown, D., 1992, The Nature of Buddhist Ethics, Macmillan Press LTD, London.

Kraut, Richard, "Aristotle's Ethics", The Stanford Encyclopedia of Philosophy (Summer 2014 Edition), Edward N. Zalta (ed.), URL = <http://plato.stanford.edu/archives/sum2014/entries/aristotle-ethics/>.

Lucke, J., 2013, "Towards a Smart Population: A Public Health Framework for Cognitive Enhancement", Neuroethics, vol. 6, no. 2, pp. 419-427.

Lucke, J., 2012, "Emperical Research on Attitudes Towards Cognitive Enhancement Is Esseantial to Inform Policy and Practice Guidelines", American Journal of Bioethics Primary Research, vol. 3, no. 1, 58-60.

Maher, B., 2008, “Poll results: look who's doping”, Nature, vol. 452, pp. 674-675.

McCabe, S.E., Knight, J.R., Teter, C.J. \& and Wechsler, H., 2005, "Non-medical use of prescription stimulants among US college students: prevalence and correlates from a national survey", Addiction, vol. 100, no. 1, pp. 96 - 106.

Ortner, S.B., 1973, "Sherpa Purity", American Anthropologist, vol. 75, no. 1, pp. 4963.

Partridge, B., Lucke, J., \& Hall, W., 2012, "A Comparison of Attitudes Towards Cognitive Enhancement and Legalized Doping in Sport in Community Sample of Australian Adults, American Journal of Bioethics Primary Research, vol. 3, no. 4, pp. 81-86.

Persson, I. \& Savulescu, J. 2008, "The Perils of Cognitive Enhancement and the Urgent Imperative to Enhance the Moral Character of Humanity", Journal of Applied Philosophy, vol. 25, no. 3, pp. 162-177.

Polusny, M.A., Erbes, C.R., Thuras, P., et al., 2015, “Mindfulness-Based Stress Reduction for Posttraumatic Stress Disorder Among Veterans: A 
Randomized Clinical Trial. Journal of the American Medical Association, vol. 314 , no. 5 , pp. $456-465$.

Racine, E. \& Forlini, C., 2010, "Cognitive Enhancement Lifestyle Choice or Misuse of Prescription Drugs?: Ethics Blind Spots in Current Debates", Neuroethics, $3,1-4$.

Rogers, C.R., 1951, Client centred therapy, Constable, London.

Ruth, D., 2005, 18/08/2005 last update, History of Buddhism in Britain, BBC.co.uk, [Online]. URL <http://www.bbc.co.uk/religion/religions/buddhism/history/britishbuddhi sm_1.shtml>.

Saddhatissa, H., 2003, Buddhist Ethics, Wisdom Publications, Boston.

Sahakian, B.J. \& Morein-Zamir, S., 2011, "Neuroethical issues in cognitive enhancement", Journal of Psychopharmacology, vol. 25, no. 2, pp. 197-204.

Savulescu, J., 2006, “Justice, Fairness, and Enhancement”, Annals of the New York Academy of Science, vol. 1093, pp. 321-338.

Sententia, W., 2004, "Neuroethical Considerations: Cognitive Liberty and Converging Technologies for Improving Human Cognition", Annals of the New York Academy of Sciences, vol. 1013, pp. 221-228.

Singh, I., Bard, I., Jackson, J., 2014, Robust Resilience and Substantial Interest: A Survey of Pharmacological Cognitive Enhancement among University Students in the UK and Ireland. PLoS ONE, vol. 9, no. 10, pp. 1-12.

Small, M., 2008, "Ethical Imperialism" in RW Kolb (ed.), Encyclopaedia of business ethics and society, SAGE Publications, Inc., Thousand Oaks, CA, pp. 782-783.

Stenhouse, L., 2013, "The Study of Samples and the Study of Cases", British Educational Research Journal, vol. 6, no. 1, pp. 1-6.

Turner, L., 2004, "Bioethics in Pluralistic Societies", Medicine, Health Care and Philosophy, vol. 7, no. 2, pp. 201-208. 